Research Article

\title{
Research on Supernetwork Equilibrium about Deep Convergence of Enterprise Alliance for Breakthrough Innovation
}

\author{
Yumei Liu, ${ }^{1,2}$ Xin Wen ${ }^{1},{ }^{1}$ and Xiangfei Meng ${ }^{3}$ \\ ${ }^{1}$ Shenyang University of Technology, Shenyang 110087, China \\ ${ }^{2}$ Liaoning Police and Justice Management College, Shenyang 110161, China \\ ${ }^{3}$ Liaoning Police College, Dalian 116000, China \\ Correspondence should be addressed to Xin Wen; wenxin@sut.edu.cn
}

Received 26 April 2021; Revised 6 July 2021; Accepted 17 August 2021; Published 26 August 2021

Academic Editor: Piergiulio Tempesta

Copyright ( $\odot 2021$ Yumei Liu et al. This is an open access article distributed under the Creative Commons Attribution License, which permits unrestricted use, distribution, and reproduction in any medium, provided the original work is properly cited.

The realization of breakthrough innovation with high risk and uncertainty has always been the focus of the theory and practice of technological innovation. Based on the supernetwork theory, this paper constructs a supernetwork equilibrium model about deep convergence of enterprise alliance for breakthrough innovation and uses numerical simulation tools to find out the equilibrium conditions for deep convergence of enterprise alliance in different stages of breakthrough innovation. It is not only conducive to understand the process of enterprise alliance's deep convergence in "Creativity-Research-Production-Sales" but also helpful to understand the roles that deep convergence in enterprise alliance can play in achieving breakthrough innovation. It not only expands the existing research on breakthrough innovation but also provides a scientific reference for the deep convergence of enterprise alliance in practice.

\section{The Introduction}

Breakthrough innovation is considered a kind of discontinuous innovation that breaks away from the original technological trajectory and significantly reduces the product cost or improves the product performance in a revolutionary way, which will have a huge impact on the market and industry [1]. The formation of breakthrough innovation has great contingency and uncertainty, and it is difficult for enterprises to realize the process of breakthrough innovation from technology research, technology productization to marketization by themselves. With the accelerated development of science and technology, the innovation paradigm of enterprises has changed from "closed competition" to "open collaboration," and the boundary about organizations has been gradually diluted. Organizational cooperation has become the key content in the field of breakthrough innovation. Enterprises need to acquire a large amount of internal and external resources and establish enterprise alliance partnerships, so as to obtain more development opportunities through deep convergence, collaboration, and cross-border search. At present, more and more enterprises begin to explore the convergence mode that take themselves as the leading factors and combine the multiple innovation subjects. The enterprise alliance of "multialliance and multiproject" has been paid attention to in practice and research as the most representative convergence mode. The diversity of alliance combinations is conducive to the generation of breakthrough innovation [2]. Enterprises build alliance network relations by selecting members with different industry attributes or crossing different knowledge boundaries, which can help to enhance the convergence among organizations and facilitate the transfer and absorption of enterprises' knowledge in the stage of technology research, and it is conducive to share the material supply, marketing, and sales channels in the stage of commercialization. It is also helpful to improve the innovation ability of alliance enterprises and accelerate the pace of enterprise innovation [3]. The diversity of technology, information, production capacity, and users within the alliance enterprise lays a foundation for the enterprise to acquire abundant 
heterogeneous innovation resources, which is conducive to the formation of breakthrough innovation and to reduce the risks and uncertainties in the process of breakthrough innovation, so as to avoid the "locking effect" of the enterprise and realize risk sharing [4]. Therefore, enterprise innovation strategic alliances can significantly promote enterprise breakthrough innovation [5], and the establishment of a benign alliance network relationship has important practical significance for the breakthrough innovation of enterprises.

The deep convergence of enterprise alliance for the breakthrough innovation is not only the convergence across the enterprises but also a process in which innovation participants participate in the generation of new technological ideas, the formation, and marketization of new products. The collaborative innovation model among alliance enterprises lays an important foundation for leapfrog development and promotes the occurrence of deep convergence. Some scholars have realized that knowledge, technology, products, and market are closely attached to the collaborative cooperation among enterprises. Due to the high risk of breakthrough innovation activities and the uncertainty of the result of deep convergence among alliance enterprises, it will bring delayed or even loss-making economic returns to enterprise alliances. Therefore, alliance enterprises should establish a comprehensive system of deep convergence, and the supernetwork theory provides ideas for this study to explore the process of deep convergence within the enterprise alliance based on the knowledge characteristics, technical characteristics, product characteristics, and market characteristics. This paper combines the collaborative cooperation of alliance enterprises with the deep convergence of "Creativity-Research-ProductionSales" by drawing on the method of supernetwork and finds out the supernetwork equilibrium conditions about the deep convergence of the enterprise alliance for breakthrough innovation which is of great significance for enterprises to achieve breakthrough innovation, establish the alliance partnerships, and explore the deep convergence about each stage of breakthrough innovation.

This study mainly includes the following four steps: the first step is to deeply study the stages of breakthrough technological innovation and deep convergence and then use the supernetwork theory to connect them into the deep convergence supernetwork of enterprise alliance for breakthrough innovation. The second step is to construct the deep convergence supernetwork, which is composed of knowledge convergence subnetwork, technology convergence subnetwork, production convergence subnetwork, and market convergence subnetwork. The third step is to construct and analyze the supernetwork equilibrium model and propose the mathematical model. Finally, in the fourth step, the problems are described and the parameters are set, the mathematical model of the integrated structure is built, and then the simulation results are analyzed. We put forward the optimization and management strategies of the supernetwork equilibrium model about the deep convergence of enterprise alliance for breakthrough innovation, as shown in Figure 1.

\section{Theoretical Basis}

2.1. The Stage of Breakthrough Innovation Formation. The formation of breakthrough innovation with high uncertainty and contingency has caused great difficulties to the research of breakthrough innovation; however, the stage characteristics of breakthrough innovation are relatively clear. We can grasp the results of breakthrough innovation starting from different stages of breakthrough innovation. The formation of breakthrough innovation needs to be based on the analysis of the characteristics in each stage. The origin of breakthrough innovation can be traced back [6], and the process or stage of breakthrough innovation can be dynamically tracked. Existing studies have many ways to classify the stage of breakthrough innovation but generally include the creativity stage, technology stage, products stage, and market stage [7]. The creativity stage is fuzzy, unconventional, dynamic, and uncertain, and the front-end planning is unpredictable, with few prior strategies [8]. The generation of fuzzy front-end creativity needs the convergence and creation of diversified creative knowledge [9]. The technology stage is a process from the generation of ideas to the emergence of new technologies. Breakthrough technology is a new technology that has separated itself from the existing technological trajectory, showing the characteristics of diversity, frontier, complexity, pioneering, breakthrough, and convergence [10]. Therefore, higher requirements are imposed on enterprises, forcing enterprises to establish cooperation with external organizations and obtain information, knowledge, capital, and other resources through higher network structure, relationship, and cognitive embeddedness of alliance enterprise [11]. The production stage is the result of the joint action of each enterprise. The enterprise alliance cooperates with each other to provide supporting measures such as equipment and services. In the market stage, the restructuring of the market pattern is the main feature of breakthrough innovation.

2.2. Deep Convergence. At present, we focus more on technology convergence; the convergence is not just a single, isolated phenomenon at the technological level. In the process of the emergence and development of convergence, not only do the relevant basic and applied science provide important support for convergence but also the industrial convergence is closely related. In addition, it is also affected by the social economy, legal rules, and users and other influencing factors. Therefore, we can understand and master the operation mechanism and dynamic characteristics of deep convergence including technology convergence more accurately and comprehensively by adopting the system point of view. Acklin divided the whole convergence process into four time series: knowledge convergence, technology convergence, application convergence, and industry convergence through observation and practical case analysis. Curran et al. proposed a similar framework, but the difference is that he replaced application convergence with market convergence and proposed the convergence evolution framework of "knowledge convergencetechnology convergence-market convergence-industry convergence" [12]. 


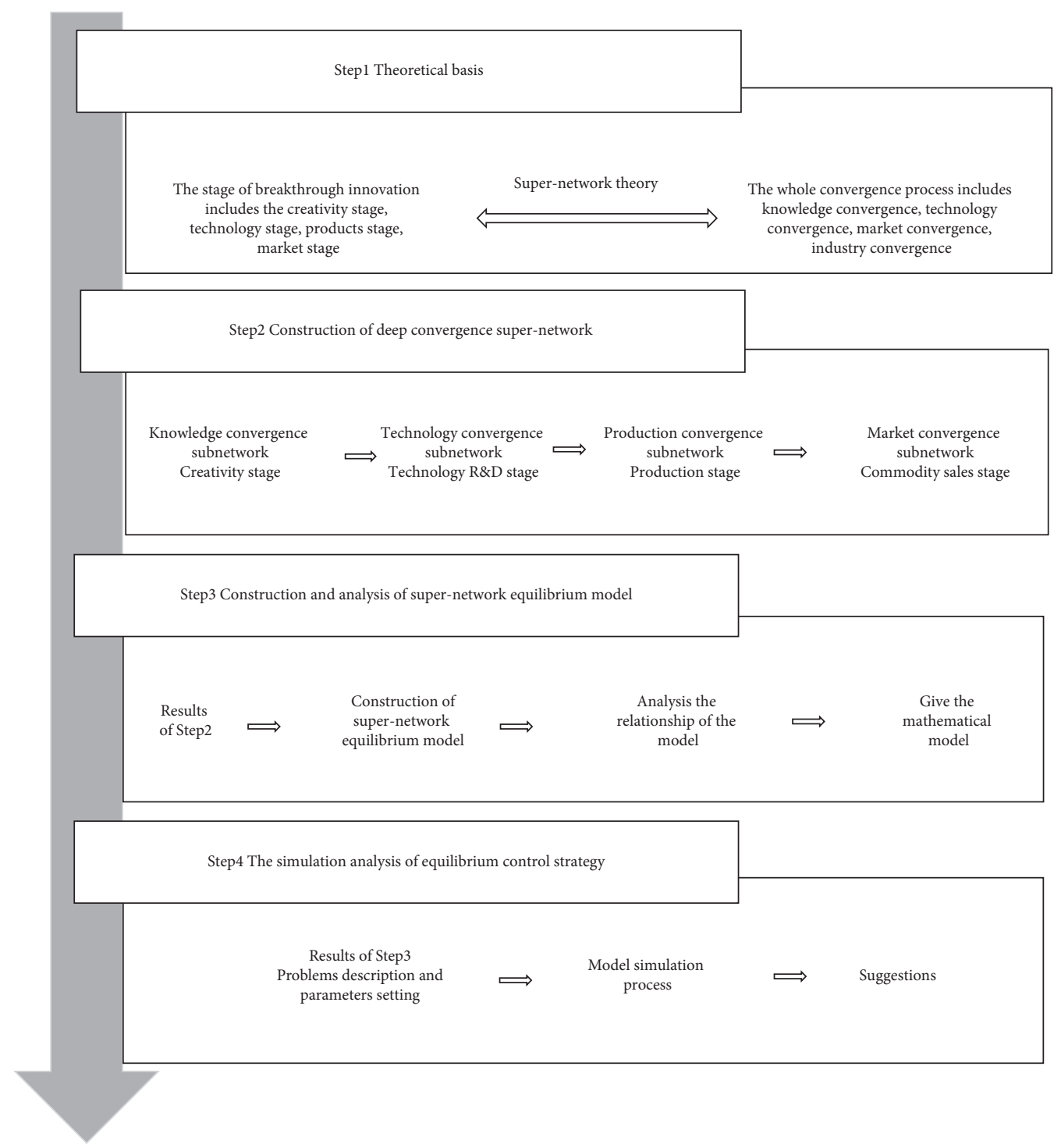

Figure 1: Overall process.

In this paper, the deep convergence of enterprise alliance for breakthrough innovation starts from cross-referencing among various scientific fields and gradually goes into the multidisciplinary knowledge convergence. As the distance about basic disciplines is gradually shortened and the technology is constantly developing, technology convergence occurs, and it further promotes the emergence of new products, leads to the emergence of market convergence, and finally completes the industrial convergence. It is the process of breakthrough technology from formation to marketization and finally subverting the market and industry, as shown in Figure 2.

2.3. Supernetwork Theory. Supernetwork theory is established on the basis of complex network research, which is used to describe the interaction and influence in different networks. Supernetwork is a method to study multidimensional equilibrium and optimization of various important attributes. It goes beyond the real network and is at the forefront of graph theory and network science. Supernetwork has the characteristics of multilayer, multidimension, multiattribute, multicriteria, convergence, and congestion. Supernetwork is composed of the subnetwork with related logical relationships, and each subnetwork is a relatively independent operation of the subsystems, which interact with each other through the connection and mutual influence between the nodes. The reliability of the whole network depends on the interaction and status of each subnetwork.

This study uses the supernetwork theory to connect the stages of breakthrough technological innovation and the stages of deep convergence into the deep convergence supernetwork of enterprise alliance for breakthrough innovation. Breakthrough innovation cannot be separated from the role of the network [13]. The success of breakthrough innovation requires the contributions and convergence of knowledge, information, technology, products, and markets, and the formation of breakthrough innovation comes from the joint efforts of many participants in the 


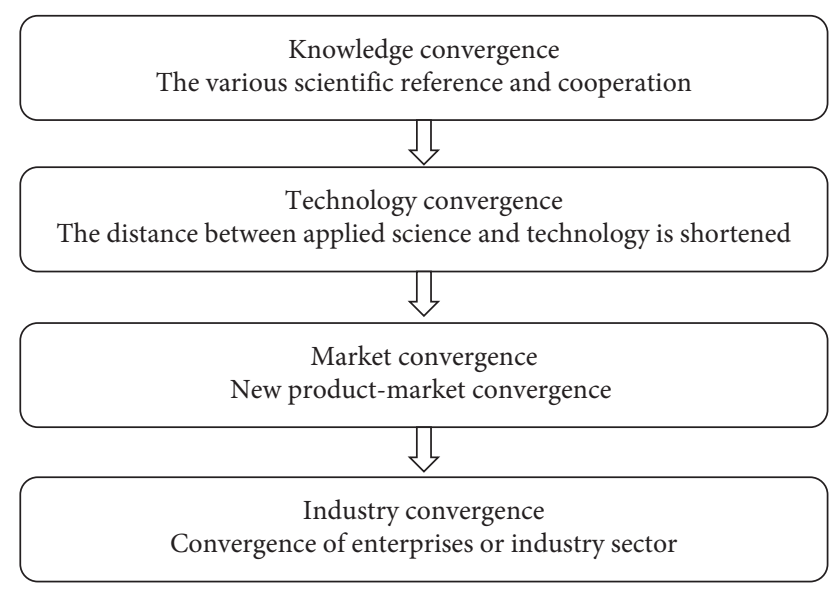

Figure 2: The processes of convergence.

network. The deep convergence supernetwork of breakthrough innovation is made up of many enterprises as nodes with different roles. The conflict about the demand for external resources and the nonsharing of internal resources among enterprises leads to the formation of a breakthrough innovation network which provides enterprises with knowledge, technology, equipment, market, and other resources, so as to ensure the innovation performance of the enterprise. So, this paper argues that the composition of deep convergence supernetwork of breakthrough innovation should be viewed from both horizontal and vertical aspects: first, from the perspective of the enterprise, deep convergence supernetwork of breakthrough innovation is composed of the interaction mode among the alliance enterprises. In the network, enterprises can make use of various interorganizational relations to obtain resources [14], which provides a guarantee for the realization of breakthrough innovation. Second, from the perspective of the breakthrough innovation stages and deep convergence stages, the formation of deep convergence supernetwork of breakthrough innovation goes through the knowledge convergence stage, technology convergence stage, production convergence stage, and market convergence stage. At each stage, different participants including alliance enterprises cooperate with each other and make efforts to construct the supernetwork and ensure the formation of breakthrough innovation, as shown in Table 1.

\section{Construction of Deep Convergence Supernetwork of Enterprise Alliance for Breakthrough Innovation}

Breakthrough innovation is the process of evolving from breakthrough technology to product and finally entering the market. The value of breakthrough innovation is realized only through a complete experience of "Creativity-ResearchProduction-Sales."

3.1. Knowledge Convergence Subnetwork (Creativity Stage). Breakthrough innovations often require a large investment of heterogeneous knowledge that cannot all be acquired from the internal organization. According to resource-based theory and social network theory, acquisition of knowledge from outside can not only relieve the resources constraint of enterprises but also obtain complementary resources, so as to avoid the rigid problems of breakthrough innovation ability caused by the single source of knowledge [15]. According to the theories of network partnership and interorganizational learning, enterprise alliance can significantly promote the acquisition, interpretation, utilization, and creation of interorganizational tacit knowledge and thus accelerate the breakthrough innovation of enterprises [16]. According to the theory of knowledge-based, enterprises need to invest a lot of new knowledge to implement breakthrough innovation, but how to acquire new knowledge from external organizations effectively is the key to ensure the realization of breakthrough innovation [17]. Enterprise alliance is conducive to enhancing the degree of interaction between enterprises, and the exchange and communication among enterprises can not only close the distance of enterprises but also help to improve the level of knowledge convergence among enterprises. The network relationship of enterprise alliance builds a good communication and exchange platform for enterprises. The alliance enterprises can acquire a large amount of external knowledge through this platform and generate new knowledge through absorption, digestion, utilization, and knowledge convergence, which is conducive to the formation of breakthrough innovation.

\subsection{Technology Convergence Subnetwork (Technology R\&D} Stage). In the context of the current technology convergence, the technology structure level, innovation mode, and innovation degree have changed greatly. Driven by breakthrough innovation, previously unrelated technologies are beginning to merge with each other [18]. The cross-border innovation of technology can break the shackles of the previous knowledge structure on the technological trajectory [19]. In this mode of innovation, many previously unrelated domains or technologies that span different knowledge structures are combined to produce new functions or applications, thus enabling technological innovation to complete the leapfrog of the technological trajectory. Breakthrough innovation results from the technological trajectory transition [20], so the convergence of different technologies promotes the evolution of breakthrough innovation. Enterprise is the main driving force of technological development, which obtains the technologies through technology acquisition, licensing, authorization, or equity alliances and utilizes the technologies to achieve technology convergence. The enterprise alliance makes the technology convergence barrier disappear. Breakthrough innovation is not limited to a single enterprise, but the linkage of multiple enterprises. The convergence of various technologies within the enterprise alliance forms an intricate network, which brings advantages that a single enterprise cannot achieve. Technology convergence is an important means of enterprise alliance cooperation and a necessary prerequisite for the reengineering of production technology and process flow. 
TABLE 1: Inspiration from the literature.

\begin{tabular}{|c|c|c|}
\hline & Literature research & In this study \\
\hline $\begin{array}{l}\text { The stage of breakthrough } \\
\text { innovation formation }\end{array}$ & $\begin{array}{c}\text { The creativity stages, technology stages, products stage, } \\
\text { and market stage }\end{array}$ & \\
\hline $\begin{array}{l}\text { The stage of deep } \\
\text { convergence }\end{array}$ & $\begin{array}{c}\text { Knowledge convergence, technology convergence, } \\
\text { application convergence (market convergence), and } \\
\text { industry convergence }\end{array}$ & $\begin{array}{l}\text { On the basis of the above literature, the author thinks } \\
\text { that deep convergence supernetwork of enterprise } \\
\text { alliance for breakthrough innovation is a }\end{array}$ \\
\hline Supernetwork theory & $\begin{array}{l}\text { In a supernetwork, subnetworks are described by a "set } \\
\text { of points," connected by edges or arcs between each } \\
\text { "set of points." Supernetwork is composed of multiple } \\
\text { subnetworks, and each subnetwork is a relatively } \\
\text { independent subsystem, which influences each other } \\
\text { through the connection between nodes }\end{array}$ & $\begin{array}{l}\text { supernetwork composed of knowledge convergence } \\
\text { subnetwork, technology convergence subnetwork, } \\
\text { production convergence subnetwork, and market } \\
\text { convergence subnetwork, four layers of subnetwork, } \\
\text { with different enterprises in the alliance as nodes }\end{array}$ \\
\hline
\end{tabular}

3.3. Production Convergence Subnetwork (Production Stage). In the early stage of breakthrough technology development, it requires very high costs and $R \& D$ expenses. In many cases, although the technology is advanced, it does not conform to the expectations of the market, which is not cost-effective. Breakthrough technologies come to the forefront only when they become products that can be sold. The stage of production convergence is based on the interaction among the alliance enterprises and the alliance enterprises are scattered in different parts of the production chain, which constitutes the production convergence network for breakthrough innovation. Alliance enterprises in the network can be suppliers, producers, supporters of complementary infrastructure, or providers of production and supporting measures to meet the needs of breakthrough innovation productization. With the continuous development of information and production technology, "fragmented" production has become a new production mode for enterprises to exploit their strengths, circumvent their weaknesses, and expand their profits [21]. The emergence of the production division of labor makes it unnecessary for enterprises to undertake all production processes [22]. Alliance enterprises take advantages of alliance networks to speed up the development of new products and increase the possibility of breakthrough innovation products [23].

\subsection{Market Convergence Subnetwork (Commodity Sales} Stage). The success of breakthrough innovation means the commercialization of commodities or technologies [24]. With the acceleration of scientific progress and technological innovation, enterprises face a tougher business environment and it is difficult for enterprises to realize breakthrough innovation through limited internal resources. It is the key path for many enterprises to realize the "last mile" of breakthrough innovation by breaking organizational boundaries, obtaining external resources, and building the market convergence network of alliance enterprises. McEvily and Zaheer pointed out that those enterprises can obtain valuable information, capture new business opportunities, and maintain sustainable competitive advantage through interorganizational networks [25]. Many enterprises construct enterprise alliance networks to develop markets and achieve breakthrough innovation [26]. As breakthrough innovation focuses on the development of new businesses and new markets, the enterprise skills required for its commercialization are different from those required in the rest of the stage, focusing on collecting and processing the information of customer requirement and competitor capability [27]. With the help of the marketing network and other resources of alliance partners, it is easier to convert technical resources into salable products and produce more marketable products. With the deep convergence of knowledge, technology, and production in the alliance enterprises in the early stage, the product categories of the enterprise are increasingly cross-border, the market boundary is gradually blurred, and the market of enterprise alliance forms convergence. Market convergence is a process in which the alliance enterprises contribute their own original market and create a new market, enterprises are increasingly connected, multiple parties share information resources, the scope of convergence is expanding, and the network structure is optimized, as shown in Figure 3.

Deep convergence of enterprise alliance for breakthrough innovation involves all types of activities inside the enterprise alliance, as well as the resources to support breakthrough innovation activities. It is an organic system composed of a knowledge convergence network, technology convergence network, production convergence network, and market convergence network. Deep convergence of enterprise alliance for breakthrough innovation has the characteristics of supernetwork, and the supernetwork structure model can be constructed, as shown in Figure 4.

The deep convergence of enterprise alliance for breakthrough innovation is characterized by multiagent, multilevel, multiattribute, multicriteria, and other features, as shown in Table 2.

\section{Construction and Analysis of Supernetwork Equilibrium Model about Deep Convergence of Enterprise Alliance for Breakthrough Innovation}

4.1. Construction of Supernetwork Equilibrium Model about Deep Convergence of Enterprise Alliance for Breakthrough Innovation. It is assumed that there are $K$ individuals in the supernetwork model $S$ about deep convergence of enterprise alliance for breakthrough innovation. One of these individuals exists in the four subnetworks of the deep 


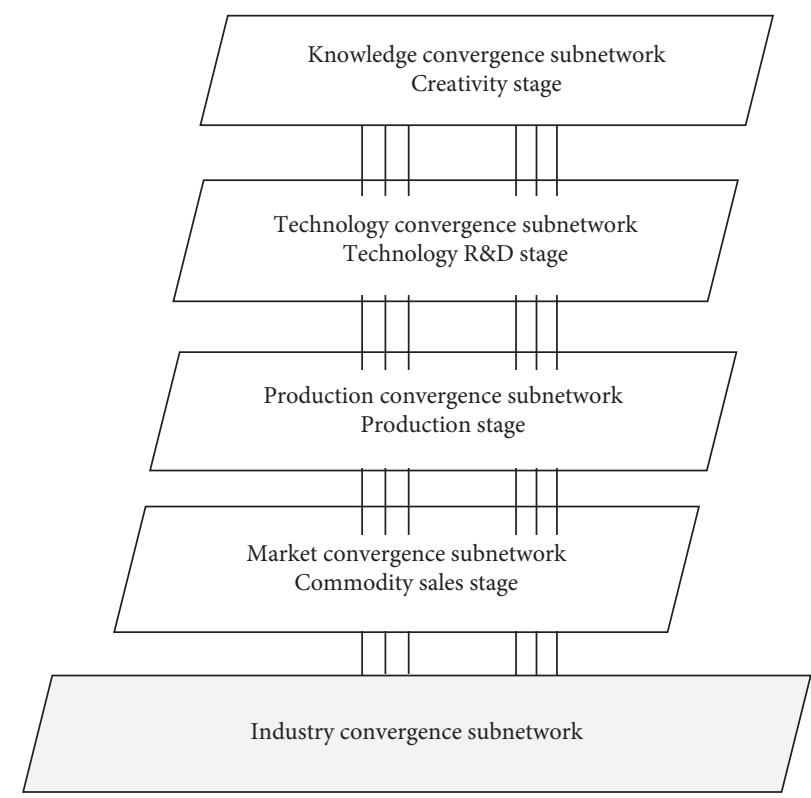

FIGURE 3: The supernetwork model about deep convergence of enterprise alliance for breakthrough innovation.

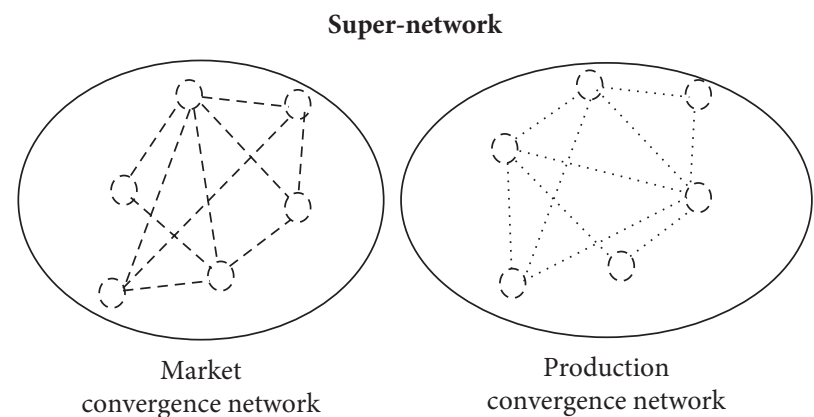

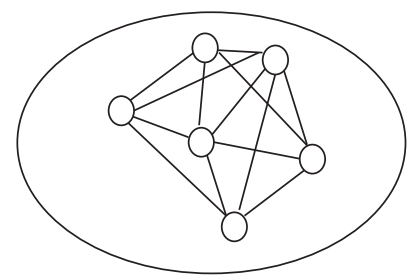

Knowledge convergence network

- - - Market information flow Materials flow

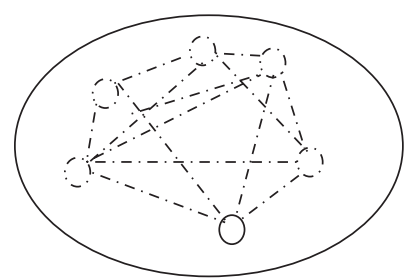

Technology convergence network

-..- Technology flow _ Knowledge flow

FIGURE 4: Schematic diagram of enterprise alliance deep convergence supernetwork for breakthrough innovation.

convergence supernetwork model of enterprise alliance for breakthrough innovation and has corresponding relationships, which is called a node in the model. $i, j$ are the two nodes in the subnetwork as shown in Figure 5.

According to the relationship analysis of the model, this paper gives the following mathematical model:

(1) In the knowledge convergence subnetwork, $s_{i j}$ is the level of knowledge flow between nodes $i$ and $j$, values range from 0 to 1 , the cost of each knowledge flow $s_{i j}$ is $D_{i j}=D_{i j}\left(s_{i j}\right)$, income is $W_{i j}$, and $W_{i j}=W_{i j}\left(s_{i j}\right)$.
The competition and cooperation relationship in the breakthrough innovation enterprises alliance will lead to knowledge spillover risk in the process of cooperation, which is not conducive to knowledge sharing. As a result, the cooperation effect of breakthrough innovation enterprise alliance is unsatisfactory, so the establishment of knowledge flow $s_{i j}$ has certain risk $X_{i j}$, and $X_{i j}=X_{i j}\left(s_{i j}\right)$.

(2) In the technology convergence subnetwork, $h_{i j}$ is the technology flow level between nodes $i$ and $j$, 
TABle 2: The characteristics of deep convergence of enterprise alliance for breakthrough innovation.

\begin{tabular}{|c|c|c|}
\hline No. & Characteristics & Explanation \\
\hline 1 & Multiagent & $\begin{array}{c}\text { The enterprise alliance involves a number of subjects, including R\&D enterprises, production enterprises, and sales } \\
\text { enterprises }\end{array}$ \\
\hline 2 & Multilevel & $\begin{array}{l}\text { Knowledge convergence network and technology convergence network are the bottom layers, production } \\
\text { convergence network is the middle layer, and market convergence network is the top layer }\end{array}$ \\
\hline 3 & Multiattribute & $\begin{array}{l}\text { In the enterprise alliance, the multiple subjects have different goals and task attributes, and the relations among the } \\
\text { subjects are also diversified }\end{array}$ \\
\hline 4 & & The different objectives and demands of the $s$ \\
\hline 5 & & Due to the limited resources, all kinds of flows will be limited \\
\hline 6 & Coordination & The subjects of all levels can carry out feedback and cooperation \\
\hline
\end{tabular}

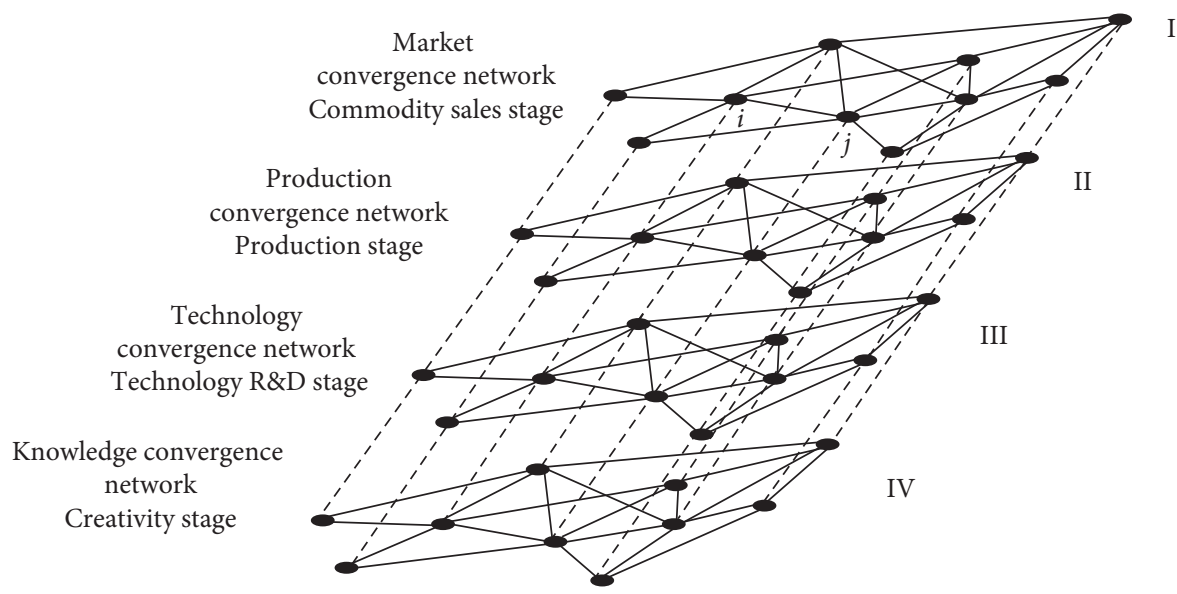

Figure 5: Three-dimensional hierarchical relationship of enterprise alliance deep convergence supernetwork for breakthrough innovation.

technology can flow within breakthrough innovation enterprise alliance through technology acquisition, licensing, authorization, or equity alliances. $h_{i j}$ means technology flows from node to node, and technology convergence is realized under certain rules to form a breakthrough technology, values range from 0 to 1 , the cost of each technology flow $h_{i j}$ is $C_{i j}=C_{i j}\left(h_{i j}\right)$, income is $E_{i j}$, and $E_{i j}=E_{i j}\left(h_{i j}\right)$. The "ubiquitous innovation network" not only provides the enterprise alliance with rich resources for breakthrough innovation but also brings the risks of "loss of control" and "knowledge loss" to the enterprise alliance, so the establishment of technology flow $h_{i j}$ has certain risk $R_{i j}$, and $R_{i j}=R_{i j}\left(h_{i j}\right)$.

(3) In the production convergence subnetwork, technology is transformed into products to realize breakthrough technology materialization, $i, j$ are two nodes, $q_{i j}$ represents the flow of materials among nodes, $q_{i j}$ is a comprehensive index of interenterprise relations, infrastructure conditions, exchange of production information, implementation and management degree of production, and standardization degree of production and manufacturing, values range from 0 to 1 , the cost of establishing the flow of materials $q_{i j}$ is $B_{i j}, B_{i j}=B_{i j}\left(q_{i j}, h_{i j}\right)$, benign materials flow $q_{i j}$ can gain income $U_{i j}$, and $U_{i j}=U_{i j}\left(q_{i j}\right)$, which is the revenue function $q_{i j}$.
(4) In the market convergence subnetwork, $i, j$ are two nodes, $p_{i j}$ represents the flow of market information between nodes, which is a comprehensive reflection of meeting customer needs, understanding the information of competitors, convergence of resources and capabilities, and marketization operation, the value of $p_{i j}$ is between 0 and 1 , the cost of establishing the flow of market information $p_{i j}$ is $A_{i j}$, $A_{i j}=A_{i j}\left(p_{i j}, q_{i j}\right)$, benign market information flow $p_{i j}$ can gain income $V_{i j}$, and $V_{i j}=V_{i j}\left(p_{i j}\right)$.

$s_{i j}, h_{i j}, q_{i j}$, and $p_{i j}$ are the decision variable of the model and they are the comprehensive indicators, which need to be quantified. This paper constructs the four indicators based on relevant studies, as shown in Table 3 .

The construction of the above functions is based on the previous research on the deep convergence of enterprise alliances. For example, the cost of establishing market information flow in nodes is affected by $p_{i j}$. Because production has an impact on the flow of market information, this paper considers that the cost of market information flow is the function of $p_{i j}$ and $q_{i j}$. Similarly, the materials flow is affected by the technology flow, so the cost of materials flow is a function of $q_{i j}$ and $h_{i j}$. At the same time, the "flow" in networks will bring some revenues, which will form the revenue function in different network systems. This paper assumes that all the functions above are continuous for the convenience of research.

The goal of an individual in the supernetwork is the maximum revenue of knowledge flow, technology flow, 
TABLE 3: Evaluation indexes of decision variables.

\begin{tabular}{|c|c|c|c|}
\hline Meaning & $\begin{array}{l}\text { First level } \\
\text { indicators }\end{array}$ & Second level indicators & Third level indicators \\
\hline $\begin{array}{l}\text { The level of knowledge flow between } \\
i, j\end{array}$ & $s_{i j}$ & $\begin{array}{l}\text { Approach of knowledge flow cooperation } \\
\text { intention between nodes } \\
\text { The level of relationships between nodes }\end{array}$ & \\
\hline $\begin{array}{l}\text { The level of technology flow between } \\
i, j\end{array}$ & $h_{i j}$ & $\begin{array}{c}\text { Approach of technology flow } \\
\text { Cooperation intention between nodes } \\
\text { Rules of technology convergence } \\
\text { Technology convergence capability of the nodes } \\
\text { The level of relationships between nodes }\end{array}$ & \\
\hline $\begin{array}{l}\text { The level of materials flow between } \\
i, j\end{array}$ & $q_{i j}$ & $\begin{array}{c}\text { The level of relationships between nodes } \\
\text { Exchange of production information } \\
\text { Production execution management } \\
\text { The logistics level }\end{array}$ & $\begin{array}{l}\text { Process improvement } \\
\text { Adjustment of product } \\
\text { structure } \\
\text { Improvement of product } \\
\text { performance }\end{array}$ \\
\hline $\begin{array}{l}\text { The level of market information flow } \\
\text { between } i, j\end{array}$ & $p_{i j}$ & $\begin{array}{c}\text { Market information sharing between nodes } \\
\text { Understanding and integration of market } \\
\text { information } \\
\text { Marketization operation } \\
\text { Degree of meeting customer needs }\end{array}$ & $\begin{array}{l}\text { Adjustment of market } \\
\text { positioning } \\
\text { Expansion of market range } \\
\text { Adjustment of marketing } \\
\text { Adjustment of after-sales } \\
\text { service system }\end{array}$ \\
\hline
\end{tabular}

materials flow, and market information flow and the minimum risk and the minimum cost of knowledge flow, technology flow, materials flow, and market information flow. The revenue, cost, and risk of knowledge flow, technology flow, materials flow, and market information flow are defined as follows:

$$
\begin{aligned}
& \max \sum_{j=1}^{k} W_{i j}=\max \sum_{j=1}^{k} W_{i j}\left(s_{i j}\right) \\
& \max \sum_{j=1}^{k} E_{i j}=\max \sum_{j=1}^{k} E_{i j}\left(h_{i j}\right) \\
& \max \sum_{j=1}^{k} U_{i j}=\max \sum_{j=1}^{k} U_{i j}\left(q_{i j}\right) \\
& \max \sum_{j=1}^{k} V_{i j}=\max \sum_{j=1}^{k} V_{i j}\left(p_{i j}\right) \\
& \min \sum_{j=1}^{k} R_{i j}=\min \sum_{j=1}^{k} R_{i j}\left(h_{i j}\right), \\
& \min \sum_{j=1}^{k} X_{i j}=\min \sum_{j=1}^{k} X_{i j}\left(s_{i j}\right) \\
& \min \left(\sum_{j=1}^{k} D_{i j}\left(s_{i j}\right)+\sum_{j=1}^{k} C_{i j}\left(h_{i j}\right)+\sum_{j=1}^{k} B_{i j}\left(q_{i j}, h_{i j}\right)+\sum_{j=1}^{k} A_{i j}\left(p_{i j}, q_{i j}\right)\right)
\end{aligned}
$$

Suppose the weights of the above six objectives are $\alpha_{1}, \alpha_{2}, \alpha_{3}, \alpha_{4}, \alpha_{5}, \alpha_{6}, \alpha_{7}$ and $\alpha_{1}+\alpha_{2}+\alpha_{3}+\alpha_{4}+\alpha_{5}+\alpha_{6}+\alpha_{7}$ $=1$. Therefore, the objective function is shown in Model (2). 


$$
\begin{aligned}
& \max \alpha_{1} \sum_{j=1}^{k} W_{i j} s_{i j}+\alpha_{2} \sum_{j=1}^{k} E_{i j} h_{i j}+\alpha_{3} \sum_{j=1}^{k} U_{i j}\left(q_{i j}\right)+\alpha_{4} \sum_{j=1}^{k} V_{i j}\left(p_{i j}\right)-\alpha_{5} \sum_{j=1}^{k} R_{i j}\left(h_{i j}\right)-\alpha_{6} \sum_{j=1}^{k} X_{i j}\left(s_{i j}\right) \\
& \quad-\alpha_{7}\left[\sum_{j=1}^{k} D_{i j}\left(s_{i j}\right)+\sum_{j=1}^{k} C_{i j}\left(h_{i j}\right)+\sum_{j=1}^{k} B_{i j}\left(q_{i j}, h_{i j}\right)+\sum_{j=1}^{k} A_{i j}\left(p_{i j}, q_{i j}\right)\right] \\
& \text { s.t. }\left\{\begin{array}{l}
0 \leq s_{i j} \leq 1 \\
0 \leq h_{i j} \leq 1 \\
0 \leq q_{i j} \leq 1 \\
0 \leq p_{i j} \leq 1 \\
i, j=1,2, \ldots, k, \ldots, K .
\end{array}\right.
\end{aligned}
$$

According to the theoretical analysis of supernetwork and the variational inequality, the optimal solution satisfying the above equation also satisfies the following variational inequality:

$$
\begin{aligned}
& \left(\alpha_{7} \sum_{i=1}^{k} \sum_{j=1}^{k} \frac{\partial D_{i j}\left(s_{i j}^{*}\right)}{\partial s_{i j}}+\alpha_{6} \sum_{i=1}^{k} \sum_{j=1}^{k} \frac{\partial X_{i j}\left(s_{i j}^{*}\right)}{\partial s_{i j}}-\alpha_{1} \sum_{i=1}^{k} \sum_{j=1}^{k} \frac{\partial W_{i j}\left(s_{i j}^{*}\right)}{\partial s_{i j}}\right)\left(s_{i j}-s_{i j}^{*}\right) \\
& +\left[\alpha_{7}\left(\sum_{i=1}^{k} \sum_{j=1}^{k} \frac{\partial C_{i j}\left(h_{i j}^{*}\right)}{\partial h_{i j}}+\sum_{i=1}^{k} \sum_{j=1}^{k} \frac{\partial B_{i j}\left(q_{i j}^{*}, h_{i j}^{*}\right)}{\partial h_{i j}}\right)+\alpha_{5} \sum_{i=1}^{k} \sum_{j=1}^{k} \frac{\partial R_{i j}\left(h_{i j}^{*}\right)}{\partial h_{i j}}-\alpha_{2} \sum_{i=1}^{k} \sum_{j=1}^{k} \frac{\partial E_{i j}\left(h_{i j}^{*}\right)}{\partial h_{i j}}\right]\left(h_{i j}-h_{i j}^{*}\right) \\
& +\left[\alpha_{7}\left(\sum_{i=1}^{k} \sum_{j=1}^{k} \frac{\partial B_{i j}\left(q_{i j}^{*}, h_{i j}^{*}\right)}{\partial q_{i j}}+\sum_{i=1}^{k} \sum_{j=1}^{k} \frac{\partial A_{i j}\left(p_{i j}^{*}, q_{i j}^{*}\right)}{\partial q_{i j}}\right)-\alpha_{3} \sum_{i=1}^{k} \sum_{j=1}^{k} \frac{\partial U_{i j}\left(q_{i j}^{*}\right)}{\partial q_{i j}}\right]\left(q_{i j}-q_{i j}^{*}\right) \\
& +\left(\alpha_{7} \sum_{i=1}^{k} \sum_{j=1}^{k} \frac{\partial A_{i j}\left(p_{i j}^{*}, q_{i j}^{*}\right)}{\partial p_{i j}}-\alpha_{4} \sum_{i=1}^{k} \sum_{j=1}^{k} \frac{\partial V_{i j}\left(p_{i j}^{*}\right)}{\partial p_{i j}}\right)\left(p_{i j}-p_{i j}^{*}\right) \geq 0 .
\end{aligned}
$$
follows:

For the convenience of the research, the hypothesis is as

$$
\begin{aligned}
& F_{1}\left(X^{*}\right)=\alpha_{7} \sum_{i=1}^{k} \sum_{j=1}^{k} \frac{\partial D_{i j}\left(s_{i j}^{*}\right)}{\partial s_{i j}}+\alpha_{6} \sum_{i=1}^{k} \sum_{j=1}^{k} \frac{\partial X_{i j}\left(s_{i j}^{*}\right)}{\partial s_{i j}}-\alpha_{1} \sum_{i=1}^{k} \sum_{j=1}^{k} \frac{\partial W_{i j}\left(s_{i j}^{*}\right)}{\partial s_{i j}}, \\
& F_{2}\left(X^{*}\right)=\alpha_{7}\left(\sum_{i=1}^{k} \sum_{j=1}^{k} \frac{\partial C_{i j}\left(h_{i j}^{*}\right)}{\partial h_{i j}}+\sum_{i=1}^{k} \sum_{j=1}^{k} \frac{\partial B_{i j}\left(q_{i j}^{*}, h_{i j}^{*}\right)}{\partial h_{i j}}\right)+\alpha_{5} \sum_{i=1}^{k} \sum_{j=1}^{k} \frac{\partial R_{i j}\left(h_{i j}^{*}\right)}{\partial h_{i j}}-\alpha_{2} \sum_{i=1}^{k} \sum_{j=1}^{k} \frac{\partial E_{i j}\left(h_{i j}^{*}\right)}{\partial h_{i j}}, \\
& F_{3}\left(X^{*}\right)=\alpha_{7}\left(\sum_{i=1}^{k} \sum_{j=1}^{k} \frac{\partial B_{i j}\left(q_{i j}^{*}, h_{i j}^{*}\right)}{\partial q_{i j}}+\sum_{i=1}^{k} \sum_{j=1}^{k} \frac{\partial A_{i j}\left(p_{i j}^{*}, q_{i j}^{*}\right)}{\partial q_{i j}}\right)-\alpha_{3} \sum_{i=1}^{k} \sum_{j=1}^{k} \frac{\partial U_{i j}\left(q_{i j}^{*}\right)}{\partial q_{i j}}, \\
& F_{4}\left(X^{*}\right)=\alpha_{7} \sum_{i=1}^{k} \sum_{j=1}^{k} \frac{\partial A_{i j}\left(p_{i j}^{*}, q_{i j}^{*}\right)}{\partial p_{i j}}-\alpha_{4} \sum_{i=1}^{k} \sum_{j=1}^{k} \frac{\partial V_{i j}\left(p_{i j}^{*}\right)}{\partial p_{i j}} .
\end{aligned}
$$

The above variational inequality can be expressed in standard form: $F\left(x^{*}\right), x-x^{*} \geq 0, \quad F\left(X^{*}\right)=\left(F_{1}\left(X^{*}\right), F_{2}\right.$
$\left.\left(X^{*}\right), F_{3}\left(X^{*}\right), F_{4}\left(X^{*}\right)\right), X=\left(s_{i j}, h_{i j}, q_{i j}, p_{i j}\right)$, and $X^{*}=\left(s_{i j}^{*}\right.$, $\left.h_{i j}^{*}, q_{i j}^{*}, p_{i j}^{*}\right)$. 
The supernetwork equilibrium model about deep convergence of enterprise alliance for breakthrough innovation is transformed into a mathematical model of a variational inequality, which is easy to analyze.

4.2. Solving and Analysis of the Supernetwork Equilibrium Model. The model is solved from a mathematical point of view. Formula (5) represents the marginal cost of the knowledge flow in the knowledge convergence network, formula (6) represents the marginal revenue of the knowledge flow in the knowledge convergence network, and formula (7) represents the marginal risk cost of knowledge flow in the knowledge convergence network.

$$
\begin{aligned}
& \sum_{i=1}^{k} \sum_{j=1}^{k} \frac{\partial D\left(s_{i j}^{*}\right)}{\partial s_{i j}} \\
& \sum_{i=1}^{k} \sum_{j=1}^{k} \frac{\partial W_{i j}\left(s_{i j}^{*}\right)}{\partial s_{i j}}, \\
& \sum_{i=1}^{k} \sum_{j=1}^{k} \frac{\partial X_{i j}\left(s_{i j}^{*}\right)}{\partial s_{i j}} .
\end{aligned}
$$

When the marginal total cost of the knowledge flow multiplied by the corresponding weight is equal to the marginal revenue of the knowledge flow multiplied by the corresponding weight, knowledge flow reaches equilibrium; otherwise, it is not effective in maintaining such knowledge flow, as shown in the following formula:

$$
\alpha_{7} \sum_{i=1}^{k} \sum_{j=1}^{k} \frac{\partial D\left(s_{i j}^{*}\right)}{\partial s_{i j}}+\alpha_{6} \sum_{i=1}^{k} \sum_{j=1}^{k} \frac{\partial X_{i j}\left(s_{i j}^{*}\right)}{\partial s_{i j}}=\alpha_{1} \sum_{i=1}^{k} \sum_{j=1}^{k} \frac{\partial W_{i j}\left(s_{i j}^{*}\right)}{\partial s_{i j}} \text {. }
$$

The marginal total cost of technology flow in the technology convergence network is shown in formula (9), formula (10) represents the marginal cost of technology flow in the technology convergence network, formula (11) represents the marginal cost of technology flow in the production network, formula (12) represents the marginal risk cost of technology flow in the technology convergence network, and formula (13) represents the marginal revenue of technology flow in technology convergence network.

$$
\begin{aligned}
& \sum_{i=1}^{k} \sum_{j=1}^{k} \frac{\partial C_{i j}\left(h_{i j}^{*}\right)}{\partial h_{i j}}+\sum_{i=1}^{k} \sum_{j=1}^{k} \frac{\partial B_{i j}\left(q_{i j}^{*}, h_{i j}^{*}\right)}{\partial h_{i j}} \\
& \quad+\sum_{i=1}^{k} \sum_{j=1}^{k} \frac{\partial R_{i j}\left(h_{i j}^{*}\right)}{\partial h_{i j}}, \\
& \sum_{i=1}^{k} \sum_{j=1}^{k} \frac{\partial C_{i j}\left(h_{i j}^{*}\right)}{\partial h_{i j}}, \\
& \sum_{i=1}^{k} \sum_{j=1}^{k} \frac{\partial B_{i j}\left(q_{i j}^{*}, h_{i j}^{*}\right)}{\partial h_{i j}}, \\
& \sum_{i=1}^{k} \sum_{j=1}^{k} \frac{\partial R_{i j}\left(h_{i j}^{*}\right)}{\partial h_{i j}}, \\
& \sum_{i=1}^{k} \sum_{j=1}^{k} \frac{\partial E_{i j}\left(h_{i j}^{*}\right)}{\partial h_{i j}} .
\end{aligned}
$$

When the marginal total cost of technology flow multiplied by the corresponding weight is equal to the marginal revenue of technology flow multiplied by the corresponding weight, the technology flow $h_{i j}^{*}$ in the technology convergence network achieves equilibrium, as shown in the following formula:

$$
\alpha_{7}\left[\sum_{i=1}^{k} \sum_{j=1}^{k} \frac{\partial C_{i j}\left(h_{i j}^{*}\right)}{\partial h_{i j}}+\sum_{i=1}^{k} \sum_{j=1}^{k} \frac{\partial B_{i j}\left(q_{i j}^{*}, h_{i j}^{*}\right)}{\partial h_{i j}}\right]+\alpha_{5}\left[\sum_{i=1}^{k} \sum_{j=1}^{k} \frac{\partial R_{i j}\left(h_{i j}^{*}\right)}{\partial h_{i j}}\right]=\alpha_{2}\left[\sum_{i=1}^{k} \sum_{j=1}^{k} \frac{\partial E_{i j}\left(h_{i j}^{*}\right)}{\partial h_{i j}}\right]
$$

Each node is more willing to maintain such a stable level of technology flow, which is conducive to the operation of the deep convergence system of enterprise alliance for breakthrough innovation and can play the optimal role in the deep convergence system.

When the marginal total cost of materials flow in the production convergence network multiplied by the corresponding weight is equal to the marginal revenue of materials flow multiplied by the corresponding weight, the materials flow in the production convergence network in the deep convergence supernetwork model of enterprise alliance reaches equilibrium, as shown in formula (17). The equilibrium is conducive to the movement of materials, and the materials sharing among various subjects bring the best revenue. At this time, the establishment of benign materials flow can provide the guarantee for the operation of the deep convergence of the enterprise alliance. 


$$
\begin{gathered}
\sum_{i=1}^{k} \sum_{j=1}^{k} \frac{\partial B_{i j}\left(q_{i j}^{*}, h_{i j}^{*}\right)}{\partial q_{i j}}+\sum_{i=1}^{k} \sum_{j=1}^{k} \frac{\partial A_{i j}\left(p_{i j}^{*}, q_{i j}^{*}\right)}{\partial q_{i j}}, \\
\sum_{i=1}^{k} \sum_{j=1}^{k} \frac{\partial U_{i j}\left(q_{i j}^{*}\right)}{\partial q_{i j}}, \\
\alpha_{7}\left(\sum_{i=1}^{k} \sum_{j=1}^{k} \frac{\partial B_{i j}\left(q_{i j}^{*}, h_{i j}^{*}\right)}{\partial q_{i j}}+\sum_{i=1}^{k} \sum_{j=1}^{k} \frac{\partial A_{i j}\left(p_{i j}^{*}, q_{i j}^{*}\right)}{\partial q_{i j}}\right)=\alpha_{3} \sum_{i=1}^{k} \sum_{j=1}^{k} \frac{\partial U_{i j}\left(q_{i j}^{*}\right)}{\partial q_{i j}} .
\end{gathered}
$$

Similarly, when the marginal cost of market information flow multiplied by the corresponding weight is equal to the marginal revenue of market information flow multiplied by the corresponding weight, the market information flow reaches equilibrium; otherwise, it is not beneficial to maintain this kind of market information flow, as shown in formula (20).

$$
\begin{gathered}
\sum_{i=1}^{k} \sum_{j=1}^{k} \frac{\partial A_{i j}\left(p_{i j}^{*}, q_{i j}^{*}\right)}{\partial p_{i j}}, \\
\sum_{i=1}^{k} \sum_{j=1}^{k} \frac{\partial V_{i j}\left(p_{i j}^{*}\right)}{\partial p_{i j}}, \\
\alpha_{7} \sum_{i=1}^{k} \sum_{j=1}^{k} \frac{\partial A_{i j}\left(p_{i j}^{*}, q_{i j}^{*}\right)}{\partial p_{i j}}=\alpha_{3} \sum_{i=1}^{k} \sum_{j=1}^{k} \frac{\partial V_{i j}\left(p_{i j}^{*}\right)}{\partial p_{i j}} .
\end{gathered}
$$

With the help of variational inequality theory, the model is analyzed to find the optimum input in the deep convergence system of enterprise alliance for breakthrough innovation. It needs to be based on a combination of marginal revenue and marginal cost (risk), rather than simply total cost (risk) or total revenue.

In the deep convergence system of enterprise alliance for breakthrough innovation, the cost, risk, and revenue functions of each individual are different with different architecture. When the optimal solutions of subnetworks are $s_{i j}^{*}, h_{i j}^{*}, q_{i j}^{*}, p_{i j}^{*}$, the optimal state of supernetwork can be represented by the optimal solution of all subnetworks; that is, the equilibrium solution of the supernetwork can be described by $n \times 4 n$ order matrix.

$$
\begin{gathered}
{\left[\begin{array}{ccccc}
s_{11}^{*} h_{11}^{*} q_{11}^{*} p_{11}^{*} & s_{12}^{*} h_{12}^{*} q_{12}^{*} p_{12}^{*} & s_{13}^{*} h_{13}^{*} q_{13}^{*} p_{13}^{*} & \ldots & s_{1 k}^{*} h_{1 k}^{*} q_{1 k}^{*} p_{1 k}^{*} \\
s_{11}^{*} h_{21}^{*} q_{21}^{*} p_{21}^{*} & s_{12}^{*} h_{22}^{*} q_{22}^{*} p_{22}^{*} & s_{13}^{*} h_{23}^{*} q_{23}^{*} p_{23}^{*} & \ldots & s_{1 k}^{*} h_{2 k}^{*} q_{2 k}^{*} p_{2 k}^{*} \\
s_{11}^{*} h_{31}^{*} q_{31}^{*} p_{31}^{*} & s_{12}^{*} h_{32}^{*} q_{32}^{*} p_{32}^{*} & s_{13}^{*} h_{33}^{*} q_{33}^{*} p_{33}^{*} & \ldots & s_{1 k}^{*} h_{3 k}^{*} q_{3 k}^{*} p_{3 k}^{*} \\
\ldots & & & & \\
s_{11}^{*} h_{k 1}^{*} q_{k 1}^{*} p_{k 1}^{*} & s_{12}^{*} h_{k 2}^{*} q_{k 2}^{*} p_{k 2}^{*} & s_{13}^{*} h_{k 3}^{*} q_{k 3}^{*} p_{k 3}^{*} & \ldots & s_{1 k}^{*} h_{k k}^{*} q_{k k}^{*} p_{k k}^{*}
\end{array}\right]} \\
{\left[\begin{array}{ccccc}
s_{11} s_{12} K s_{1 k} & h_{11} h_{12} K h_{1 k} & q_{11} q_{12} K q_{1 k} & p_{11} p_{12} K p_{1 k} \\
s_{21} s_{22} K s_{2 k} & h_{21} h_{22} K h_{2 k} & q_{21} q_{22} K q_{2 k} & p_{21} p_{22} K p_{2 k} \\
\ldots & \ldots & \ldots & & \ldots \\
s_{k 1} s_{k 2} \ldots s_{k k} & h_{k 1} h_{k 2} \ldots h_{k k} & q_{k 1} q_{k 2} \ldots q_{k k} & p_{k 1} p_{k 2} \ldots p_{k k}
\end{array}\right] .}
\end{gathered}
$$


When the above equilibrium solution is satisfied, all individuals $i(i=1,2, \ldots, k)$ obtain the maximum revenue. As a whole, the deep convergence system of enterprise alliance for breakthrough innovation has the greatest overall revenue under the current state.

\section{The Simulation Analysis of Equilibrium Control Strategy about Deep Convergence Supernetwork of Enterprise Alliance for Breakthrough Innovation}

5.1. Problem Description and Parameter Setting. Suppose there are 3 individuals in the deep convergence supernetwork of enterprise alliance for breakthrough innovation, and the supernetwork is divided into knowledge convergence subnetwork, technology convergence subnetwork, production convergence subnetwork, and market convergence subnetwork. The 3 individuals in this supernetwork form the nodes of the system in the subnetwork at different levels. According to the previous analysis, there are 12 nodes in the whole supernetwork. In the process of simulation, the cost function, revenue function, and risk function of the individual in the deep convergence system about knowledge flow $s_{i j}$, technology flow $h_{i j}$, materials flow $q_{i j}$, and market information flow $p_{i j}$ must be given and then establish the mathematics model of deep convergence supernetwork and bring related parameters and functions into the model. Finally, the genetic algorithm is used to solve the model to find the maximum value of the objective function in the deep convergence system and the corresponding parameters, including knowledge flow $s_{i j}$, technology flow $h_{i j}$, materials flow $q_{i j}$, and market information flow $p_{i j}$.

In the order to simulate the model proposed in this paper, the following assumptions are made.

Hypothesis 1. There are 3 individuals in the supernetwork system, which exist in the knowledge convergence subnetwork, technology convergence subnetwork, production convergence subnetwork, and market convergence subnetwork at the same time, and there is a one-to-one correspondence in the four-layer network.

Hypothesis 2. The levels of knowledge flow, technology flow, materials flow, and market information flow are either positive or zero, and the negative case is not considered here; they are between 0 and $1,0 \leq s_{i j} \leq 1,0 \leq h_{i j} \leq 1,0 \leq q_{i j} \leq 1$, $0 \leq p_{i j} \leq 1$.

Hypothesis 3. The revenues, costs, and risks of individuals in the model can all be described by functions of corresponding parameters. In practice, the cost and revenues functions of individual $i$ will be different in different subnetworks,

Due to the fact that the knowledge flow $s_{i j}$, technology flow $h_{i j}$, materials flow $q_{i j}$, and market information flow $p_{i j}$ among different individuals have different influences on individual $i$, they have different functional relationships. In order to facilitate the simulation, this article assumes that the cost, revenue, and risk functions of individual $i$ are the same as those of other individuals in the same layer of the network, $\xi_{i 1}=\xi_{i 2}=\cdots=\xi_{i j}, \xi=(A, B, C, E, V, U, R)$.

Individuals can be regarded as nodes in the network, for individual $1 ; s_{11}, s_{12}$, and $s_{13}$, respectively, represent the knowledge flow between this node and other nodes in the knowledge convergence subnetwork, revenue from establishing knowledge flow $W_{1 j}=3 * \sin \left(\pi / 2 s_{1 j}\right)$, the cost $D_{1 j}=\sqrt{s_{1 j}}$, and the risk $X_{1 j}=e^{s_{1 j}}$. In the technology convergence subnetwork, $h_{11}, h_{12}$, and $h_{13}$ represent the technology flow between node 1 and other nodes, the revenue $E_{1 j}=3 * \sin \left(\pi / 2 h_{1 j}\right)$, the cost $C_{1 j}=\sqrt{h_{1 j}}$, and the risk $R_{1 j}=e^{h_{1 j}}$. In the production convergence subnetwork, $q_{11}$, $q_{12}$, and $q_{13}$ represent the materials flow between node 1 and other nodes, the revenue $U_{1 j}=2 * \sin \left((3 \pi / 2)+\pi q_{1 j}\right)$, and the cost $B_{1 j}=2 q_{1 j} /\left(0.1+h_{1 j}\right)+1.5^{q_{1 j}}$. In the market convergence subnetwork, $p_{11}, p_{12}$, and $p_{13}$ represent the market information flow between node 1 and other nodes, the revenue $V_{1 j}=2.5 p_{1 j}$, and the cost $A_{1 j}=2 \sqrt{p_{1 j}}$.

According to the requirements for knowledge value, technology value, product revenue, market revenue, risk, and cost of the system, different weights can be set to meet the actual requirements. In the simulation of this paper, the function does not have the meaning of the actual corresponding system, so for the convenience of simulation, the weight setting is not considered. In the practical application of the model, the weight can be set flexibly according to the actual requirements of the equilibrium operation about the deep convergence system of the enterprise alliance.

5.2. Model Simulation Process. According to the above assumptions and model research, the mathematical model of the integrated structure is built.

$$
\begin{aligned}
& \max 4 \sum_{j=1}^{3}\left(3 * \sin \left(\frac{\pi}{2} s_{i j}\right)-\sqrt{s_{i j}}-e^{s_{i j}}+3 * \sin \left(\frac{\pi}{2} h_{i j}\right)-\sqrt{h_{i j}}-e^{h_{i j}}+2 * \sin \left(\frac{3 \pi}{2}+\pi q_{i j}\right)-\frac{2 q_{i j}}{0.1+h_{i j}}-1.5^{q_{i j}}+2.5 p_{i j}-2 \sqrt{p_{i j}}\right) \\
& \text { s.t. }\left\{\begin{array}{l}
0 \leq s_{i j} \leq 1 \\
0 \leq h_{i j} \leq 1 \\
0 \leq q_{i j} \leq 1 \\
0 \leq p_{i j} \leq 1 \\
i, j=1,2, \ldots, k, \ldots, K .
\end{array}\right.
\end{aligned}
$$


The genetic algorithm tool in the MATLAB optimization toolbox is used for the simulation. The objective function is taken as the adaptive function, and the $\mathrm{M}$ file is compiled according to the objective function.

$$
\begin{aligned}
& \text { function } y=\text { fits }(x) \text {, } \\
& y=4 *(3 * \sin ((\mathrm{pi} / 2) * x(1))-\operatorname{power}(x(1), 0.5)-\exp (x(1))+3 * \sin ((\mathrm{pi} / 2) * x(2))-\operatorname{power}(x(2), 0.5) \\
& -\exp (x(2))+2 * \sin (3 / 2 * \mathrm{pi}+\mathrm{pi} * x(3))-(2 *(3)) /(0.1+x(2))-1.5 * x(3)+2.5 * x(4) \\
& -2 * \operatorname{power}(x(4), 0.5)) \text {; } \\
& y=-y ; \quad \text { population selection uses random uniform distribution. }
\end{aligned}
$$

5.3. Analysis of Simulation Results. The operation is stopped after 110 iterations, and the optimal value of the objective function is 2.012. It can be seen from Figure 6 that the iterative convergence of the model is faster, and the algorithm technology has strong operability and higher efficiency. The simulation results of the model show that the best level of knowledge flow should be 0.64 , the best level of technology flow should be 0.85 , the best level of materials flow should be 0.805 , the market information flow is 1 , and the overall income of individual 1 is the best. The optimal benefit of individual 1 in the system is 5.096, as shown in Figure 7.

\section{Suggestions and Implications}

6.1. Suggestions. Based on the specific numerical results obtained by model simulation and the previous analysis, this article can provide certain policy recommendations for the deep convergence system of enterprise alliance and build the deep convergence network of enterprise alliance. Enterprise alliance network has become an important way to promote enterprise innovation, and the construction of an enterprise alliance network is very important for enterprises to achieve breakthrough innovation. In order to obtain sufficient innovative resources such as knowledge, technology, production, and market, enterprises should change the practice of focusing on the development of a single field and build a whole convergence network process from creative development, breakthrough technology, production to sales, guided by market demand. It is necessary to promote the balanced flow of diversified and heterogeneous resources within the enterprise alliance network and accelerate the breakthrough innovation with the optimal enterprise alliance network relationship and strengthen and adjust the resource management of enterprise alliance. In the process of innovation, enterprise alliance should adjust resource allocation mode according to the developing situation and the macro environment and strategically build enterprise alliance network structure to ensure a diversified and lasting trust relationship in enterprise alliance, so as to obtain more abundant network resources, increase the stock of knowledge and technology in enterprise alliance, improve resource utilization efficiency, avoid the waste of resources caused by excessive flows, and enhance the level of resource flows in the deep convergence system of enterprise alliance. It is necessary to encourage core enterprises in enterprise alliance to open up innovation resources, promote cross-border convergence of different types of enterprises, guide collaborative innovation in the links about $\mathrm{R} \& \mathrm{D}$, production, and market, strengthen enterprise alliance information sharing and technical exchange and business cooperation, expand communication channels of technology, production, and market, share all kinds of supply and demand information, and use big data and cloud computing technology to carry out in-depth information mining. In short, in different stages of the breakthrough innovation, the enterprise alliance should strengthen the information exchange among enterprises, integrate resources reasonably, and reach a consensus on cooperation, so as to achieve win-win benefits for all parties within the enterprise alliance.

6.2. Implications. Breakthrough innovation is an important way for enterprises to obtain a sustainable competitive advantage, and an enterprise alliance network can promote enterprises to achieve breakthrough innovation. In this paper, the supernetwork theory is applied to construct supernetwork equilibrium model about deep convergence of enterprise alliance for breakthrough innovation. Based on the analysis of its structural relationship and balanced operation, the mathematical model of supernetwork equilibrium is given. This paper puts forward the optimization and management strategy of supernetwork equilibrium model about deep convergence of enterprise alliance for breakthrough innovation and then provides a reference for enterprise alliance to realize deep convergence and breakthrough innovation. In practice, the enterprise alliance should further promote the construction of the whole process convergence network from creative development, breakthrough technology, production to sales, promote the balanced flow of diversified and heterogeneous resources within the enterprise alliance network, and realize the breakthrough innovation with the optimal enterprise alliance network relationship. However, there are still some shortcomings in this study. In practice, the cost function, risk function, income function of knowledge flow, technology flow, materials flow, and market information flow are very complex and uncertain. For the convenience of the study, this paper assumes that the above functions are continuous. More factors can be considered to influence the supernetwork equilibrium model about deep convergence of enterprise alliance for breakthrough innovation. 


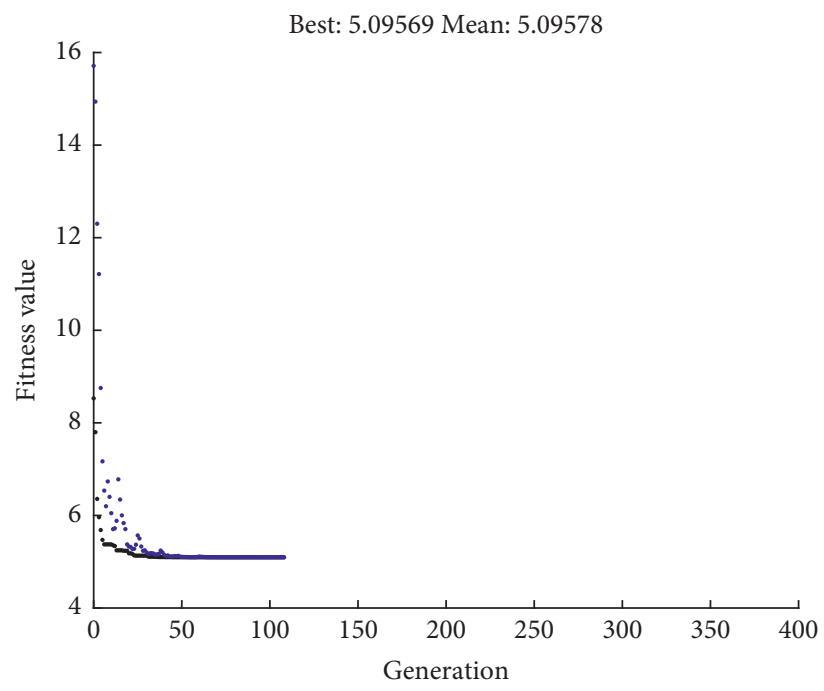

- Best fitness

- Mean fitness

FIGURE 6: Generation and best-mean fitness value.

A Optimization Tool

File Help

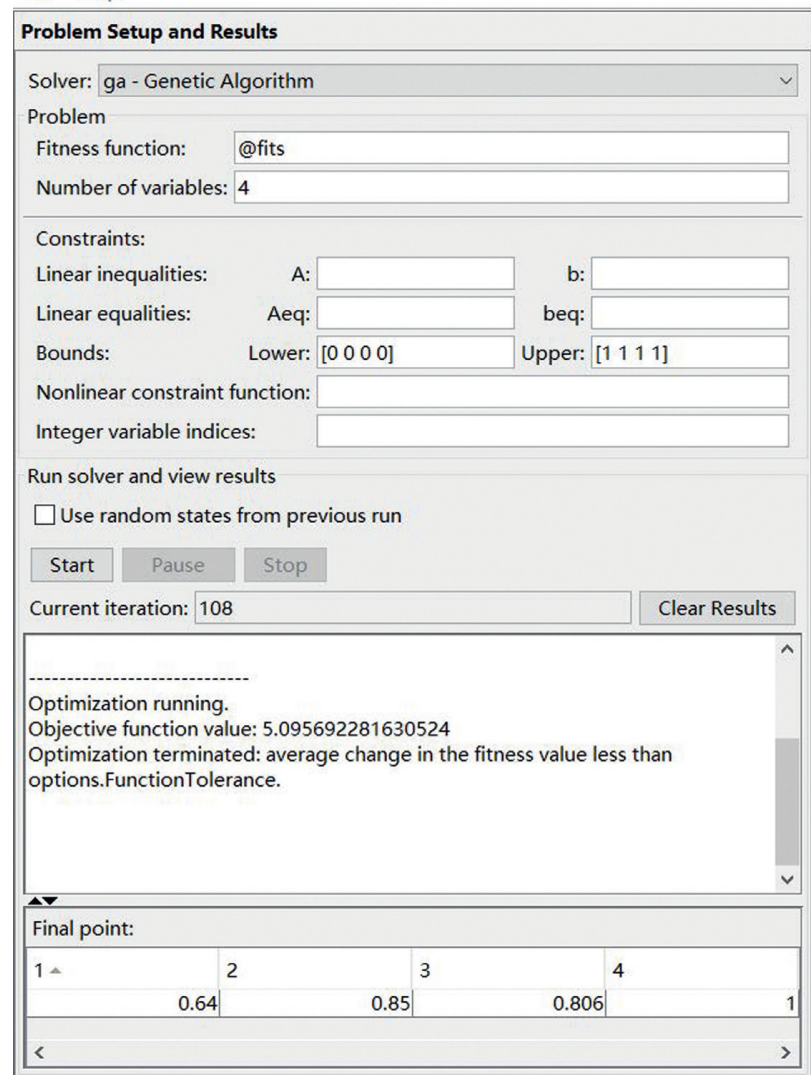

Figure 7: Model simulation results. 


\section{Data Availability}

The experimental data used to support the findings of this study are available from the corresponding author upon request.

\section{Conflicts of Interest}

The authors declare that there are no conflicts of interest regarding the publication of this study.

\section{References}

[1] H. Zhang, C. Jin, and Y. Fu, "The basis of leapfrog development of breakthrough innovation," Communications of Nature Dialectics, vol. 1, pp. 69-78, 2005.

[2] A. Wirsich, A. Kock, C. Strumann, and C. Schultz, "Effects of university-industry collaboration on technological newness of firms," Journal of Product Innovation Management, vol. 33, no. 6, pp. 708-725, 2016.

[3] A. S. Cui and G. O'Connor, "Alliance portfolio resource diversity and firm innovation," Journal of Marketing, vol. 76, no. 4, pp. 24-43, 2012.

[4] M. M. Keupp and O. Gassmann, "Determinants and archetype users of open innovation," $R$ \& D Management, vol. 39, no. 4, pp. 331-341, 2009.

[5] S. Gao and J. Gao, "Earnings management: a literature review," in Proceedings of the 2016 International Seminar on Education Innovation and Economic Management (SEIEM 2016), vol. 37, no. 1, pp. 48-57, Chongqing, China, 2016.

[6] S. Arts and R. Veugelers, "The technological origins and novelty of breakthrough inventions," in Proceedings of the 35th DRUID Celebration Conference, Barcelona, Spain, June 2013.

[7] R. Leifer, C. M. McDermott, G. C. O'connor et al., Radical Innovation: How Mature Companies Can Outsmart Upstarts, Harvard Business Press, Boston, MA, USA, 2000.

[8] P. Robbins and C. O'Gorman, "Innovating the innovation process: an organisational experiment in global pharma pursuing radical innovation," $R$ \& $D$ Management, vol. 45, no. 1, pp. 76-93, 2015.

[9] H. Luo and Q. Zhang, "Construction and measurement of the evaluation index system of breakthrough technological innovation capability of newly created technological small enterprises from the perspective of knowledge management," Operations Research and Management, vol. 25, no. 1, pp. 175-184, 2016.

[10] D. J. Kelley, A. Ali, and S. A. Zahra, "Where do breakthroughs come from? Characteristics of high-potential inventions," Journal of Product Innovation Management, vol. 30, no. 6, pp. 1212-1226, 2013.

[11] R. Verganti and A. Öberg, "Interpreting and envisioning-a hermeneutic framework to look at radical innovation of meanings," Industrial Marketing Management, vol. 42, no. 1, pp. 86-95, 2013.

[12] C.-S. Curran, S. Bröring, and J. Leker, "Anticipating converging industries using publicly available data," Technological Forecasting and Social Change, vol. 77, no. 3, pp. 385-395, 2010.

[13] S. Balachandran and E. Hernandez, "Networks and innovation: accounting for structural and institutional sources of recombination in brokerage triads," Organization Science, vol. 29, no. 1, pp. 80-99, 2018.
[14] Á. Martínez-Pérez, D. Elche, and P. M. García-Villaverde, "From diversity of interorganizational relationships to radical innovation in tourism destination: the role of knowledge exploration," Journal of Destination Marketing \& Management, vol. 11, pp. 80-88, 2019.

[15] T. J. Kull, S. C. Ellis, and R. Narasimhan, "Reducing behavioral constraints to supplier integration: a socio-technical systems perspective," Journal of Supply Chain Management, vol. 49, no. 1, pp. 64-86, 2013.

[16] P. Ritala and P. Hurmelinna-Laukkanen, "Incremental and radical innovation in coopetition-the role of absorptive capacity and appropriability," Journal of Product Innovation Management, vol. 30, no. 1, pp. 154-169, 2013.

[17] K. Z. Zhou and C. B. Li, "How knowledge affects radical innovation: knowledge base, market knowledge acquisition, and internal knowledge sharing," Strategic Management Journal, vol. 33, no. 9, pp. 1090-1102, 2012.

[18] C. Schmickl and A. Kieser, "How much do specialists have to learn from each other when they jointly develop radical product innovations?" Research Policy, vol. 37, no. 3, pp. 473-491, 2008.

[19] C. Grimpe and W. Sofka, "Search patterns and absorptive capacity: low- and high-technology sectors in European countries," Research Policy, vol. 38, no. 3, pp. 495-506, 2009.

[20] G. Dosi, "Technological paradigms and technological trajectories," Research Policy, vol. 11, no. 3, pp. 147-162, 1982.

[21] A. C. Chu, G. Cozzi, and Y. Furukawa, "Effects of economic development in China on skill-biased technical change in the US," Review of Economic Dynamics, vol. 18, no. 2, pp. 227-242, 2015.

[22] J. Xu, Q. Mao, and A. Hu, “China's import and export quality upgrading: a study based on China's evidence," The World Economy, vol. 40, no. 03, pp. 52-75, 2017.

[23] G. K. Lee, "The significance of network resources in the race to enter emerging product markets: the convergence of telephony communications and computer networking, 1989-2001," Strategic Management Journal, vol. 28, no. 1, pp. 17-37, 2007.

[24] Y. Liu, The Mechanism of Cross-Level Interest Coordination in the Network of Breakthrough Technology Innovation, Xi'an University of Technology, Xi'an, China, 2020.

[25] B. Mcevily and A. Zaheer, "Bridging ties: a source of firm heterogeneity in competitive capabilities," Strategic Manage Journa1, vol. 20, no. 12, pp. 1133-1156, 1999.

[26] G. Zhang, Y. Xi, and X. Guo, "Research on the impact of enterprise network on breakthrough innovation," Economic Review, vol. 9, pp. 75-82, 2017.

[27] B. A. Lukas and O. C. Ferrell, "The effect of market orientation on product innovation," Journal of the Academy of Marketing Science, vol. 28, no. 2, pp. 239-247, 2000. 